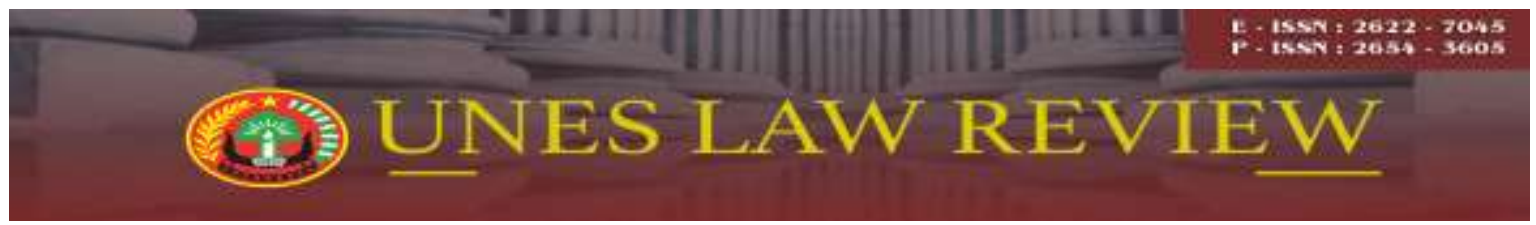

Email: uneslawreview@gmail.com

Online: http://review-unes.com/index.php/law

Volume 2, Issue 2, Desember 2019

\title{
PELAYANAN PUBLIK BAGI PENYANDANG DISABILITAS DI KOTA PADANG
}

\author{
${ }^{1)}$ Besse Fatmawanti, ${ }^{2)}$ Naldi Gantika \\ ${ }^{1)}$ Fakultas Hukum, Universitas Ekasakti, Paadang, Indonesia \\ E-mail : besse_fatmawati@yahoo.co.id \\ ${ }^{2)}$ Fakultas Hukum, Universitas Ekasakti, Paadang, Indonesia \\ E-mail : naldigantika0@gmail.com
}

\begin{abstract}
Research is important written in a journal is caused by several reasons: First, fulfillment of public services, especially for persons with disabilities, is an obligation and responsibility of the government in terms of fulfillment, both in the form of public services in the form of roads and sidewalks that are useful for the movement of persons with disabilities or for their mobility from one place to another, as well as supporting life supporters of disability. Article 2 of Law No. 39 of 1999 concerning Human Rights states that the Republic of Indonesia recognizes and upholds human rights and basic human freedoms as rights which naturally inherit to and are inseparable from humans, which must be protected, respected and enforced for the sake of increasing human dignity. Then it is also regulated that the right to protect, respect and uphold human rights is the government and in full in Article 71 of Law No. 39 of 1999 concerning Human Rights stated that "the Government is obliged and responsible to respect, protect, enforce and promote human rights regulated in this law, other laws and regulations, and international law on human rights received by the Republic of Indonesia. And it should not be forgotten also Article 72 which reads that the obligations and responsibilities of the government as referred to in Article 71 include effective implementation steps in the legal, political, economic, social, cultural, defense and security fields of the state and other fields. At least, there are 10 types of rights regulated in Law No. 39 of 1999 concerning Human Rights, a) the right to life, $b)$ the right to family and continuing descent, $c$ ) the right to selfdevelopment, d) the right to justice, e) the right to personal freedom, f) the right to security, $g$ ) the right to welfare, $h$ ) the right to welfare, i) the right to participate in government, $j$ ) the right of women, $k$ ) the rights of the child.
\end{abstract}

Kata Kunci: Pelayanan Publik, Penyandang, Disabilitas

\section{PENDAHULUAN}

Jurnal yang berjudul tentang Pelayanan Publik Bagi Penyandang Disabilitas di Kota Padang adalah berasal dari penelitian penulis yang lakukan selama 6 (enam) bulan dari Mei s/d Oktober 2018. Penelitian ini dilakukan dengan B. Fatmawanti dan Naldi Gantika 
dan keduanya adalah Dosen Fakultas Hukum Universitas Ekasakti Padang dan penelitian ini dibiayai oleh Pendidikan Tinggi (Dikti) dengan skema Penelitian Dosen Pemula (PDP) yang diajukan pada tahun 2017 yang lalu, dan dilaksanakan pada 2018 ini. Penelitian berupa produk luaran yakni jurnal nasional yang terakreditasi dan oleh karena itulah penelitian ini diangkat menjadi jurnal, dan menjadi penting ditulis karena disebabkan oleh beberapa alasan:

Pertama, pemenuhan terhadap pelayanan publik khususnya bagi penyandang disabilitas merupakan kewajiban dan tanggung jawab pemerintah dalam hal pemenuhannya, baik berupa pelayanan publik berupa jalan maupun trotoar yang berguna untuk pergerakan para panyandang disabilitas atau untuk mobilitas mereka dari satu tempat ke tempat lainnya, serta sebagai penunjang kehidupan para penunjang disabilitas. Pasal 2 UU No 39 Tahun 1999 tentang HAM disebutkan bahwa Negara Republik Indonesia mengakui dan menjunjung tinggi hak asasi manusia dan kebebasan dasar manusia sebagai hak yang secara kodrati melakat pada dan tidak terpisahkan dari manusia, yang harus dilindungi, dihormati, dan ditegakkan demi peningkatan martabat kemanusiaan.

Kemudian juga diatur yang berhak untuk melindungi, menghormati dan menegakkan HAM itu adalah pemerintah dan selengkapnya dalam Pasal 71 UU No. 39 Tahun 1999 Tentang Hak Asasi Manusia (HAM) disebutkan bahwa" Pemerintah wajib dan bertanggung jawab menghormati, melindungi, menegakkan, dan memajukan hak asasi manusia yang diatur dalam undang-undang ini, peraturan perundang-undangan lain, dan hukum internasional tentang Hak asasi Manusia yang diterima oleh negara Republik Indonesia. Dan tidak boleh dilupakan juga Pasal 72 yang berbunyi adalah kewajiban dan tanggung jawab pemerintah sebagaimana dimaksud dalam Pasal 71 meliputi langkah implementasi yang efektif dalam bidang hukum, politik, ekonomi, sosial, budaya, pertahanan dan keamanan negara dan bidang lain. Setidaknya, ada 10 jenis hak yang diatur dalam UU No 39 Tahun 1999 tentang HAM adalah a) hak untuk hidup, b) hak berkeluarga dan melanjutkan keturunan, c) hak mengembangkan diri, d) hak memperoleh keadilan, e) hak atas kebebasan pribadi, f) hak atas rasa aman, g) hak atas kesejahteraan, h) hak atas kesejahteraan, i) hak turut serta dalam pemerintahan, j) hak wanita, k) hak anak. Pemenuhan terhadap hak-hak asasi yang dilakukan oleh pemerintah itu i harus utuh dan 
semuanya, dan tidak bisa bersifat parsial. Pemenuhan hak asasi yang satu akan berdampak dan berpengaruh pada pemenuhan hak asasi yang lain.

Kedua, terkait dengan tanggung jawab tersebut, pemerintah Kota Padang dalam jangka panjang akan menjadikan kota ini tidak saja sebagai kota pendidikan akan tetapi juga kota yang ramah Hak Asasi Manusia (HAM) terutama bagi kelompok rentan penyandang disabilitas. Ketiga, untuk menuju Kota yang ramah HAM bagi penyandang disabilitas tersebut telah dilakukan berbagai upaya pembangunan pelayanan publik berupa trotoar di beberapa titik dan pusat pelayanan publik, yaitu di Jalan M. Yamin, Jalan Permindo, GOR H. Agus Salim, dan Taman Imam Bonjol.

Keempat titik pelayanan publik di jalan itu telah dibangun sarana dan prasarana yang ramah terhadap kepentingan disabilitas. Baik berupa trotoar, yang ditengahnya ada tanda-tanda untuk kepentingan disabilitas maupun kursi roda ditempat tertentu sehingga jika ada penyandang disabilitas yang melewati jalan tersebut maka dapat menggunakan fasilitas yang telah disediakan oleh Pemerintah Kota Padang.

Pembangunan fasilitas yang ramah bagi penyandang disabilitas ini dilakukan oleh Dinas Pekerjaan Umum Kota Padang dan bekerjasama dengan Dinas Sosial Kota Padang serta Badan Penanggulangan Bencana Daerah Kota Padang dengan sumber dana dari Anggaran Pendapatan Belanja Negara (APBN) dan Angaran Pendapatan Belanja Kota Padang (APBD) Kota Padang pada tahun 2017 yang lalu. Pembangunan fasilitas itu semata-mata ditujukan untuk pemenuhan hak penyandang disabilitas sebagai manifestasi dan implementasi Peraturan Daerah (Perda) Kota Padang tentang Pemenuhan dan Perlindungan Hak-hak Penyandang Disabilitas yang telah disahkan pada tahun 2015 yang lalu.

Oleh ketiga alasan itulah maka penelitian dengan judul tentang Pelayanan Publik Bagi Penyandang Disabiltas di Kota Padang relevan untuk dibuat menjadi jurnal dan diharapkan berguna bagi pengambil kebijakan di Kota Padang (walikota Padang dan DPRD Kota Padang). Agar tulisan ini lebih terarah maka hendak menyigi tentang bagaimana potret pelayanan publik di Kota Padang khususnya bagi penyandang disabilitas?.

Pertanyaan itu sangat penting dijawab karena pengaturan HAM bukan saja diatur dalam UUD 1945 sebelum perubahan, akan tetapi juga diatur pada Perubahan Kedua 
UUD 1945 yang memuat ketentuan yang lebih lengkap tentang HAM. Sebelum perubahan misalnya, perlindungan terhadap HAM dan warga negara, nampak dalam pengaturan beberapa pasal dalam batang tubuh UUD 1945, terutama Pasal 26, Pasal 27, Pasal 28, Pasal 29, Pasal 30, Pasal 31, dan Pasal 34.

Sedikitnya, pasal yang mengatur hak asasi manusia dalam UUD 1945 yang disahkan pada tanggal 18 Agustus 1945, kemungkinan karena beberapa alasan. Pertama, adanya pandangan (filsafat berpikir) dari pendiri bangsa (the founding fathers) bahwa HAM tumbuh dari paham individualisme yang bertentangan dengan pandangan/filsafat bernegara yang dianut Indonesia (ide bernegara/staatsidee), yaitu paham kekeluargaan. Kedua, belum adanya konvensi internasional yang disetujui bangsa-bangsa di dunia yang dapat dijadikan acuan bagi pengaturan hak asasi manusia dalam konstitusi masing-masing negara dunia.

\section{METODE PENELITIAN}

Metode penelitian yang telah digunakan adalah penelitian hukum empiris. Penelitian hukum empiris adalah penelitian hukum sosiologis yang dapat disbeut juga dengan penelitian lapangan. Penelitian ini bertitik tolak dari data primer Data primer adalah adalah data yang didapat langsung dari masyarakat sebagai sumber pertama dengan melalui penelitian lapangan. Perolehan data primer dari penelitian lapangan dapat dilakukan baik melalui pengamatan (obersevasi), wawancara ataupun penyebaran kuisoner. Penelitian hukum sebagai sosilogis dapat direalisasikan kepada penelitian terhadap efektivitas hukum yang sedang berlaku ataupun penelitian terhadap identifikasi hukum. Dalam hal ini adalah Peraturan Daerah No 3 tahun 2015 tentang Pemenuhan dan Perlindungan Hak-Hak Penyandang Disabilitas.

Sejauh mana pemerintah telah mengimplementasikan Perda tersebut bagi Pemenuhan dan Perlindungan Hak-Hak Penyandang Disabilitas di Kota Padang. Penelitian ini juga telah melakukan inventarisasi peraturan perundang-undangan mulai dari UUD 1945, UU, hingga Peraturan Daerah Provinsi Sumatera Barat dan Peraturan Daerah Kota Padang. Karena penelitian gabungan antara penelitian sosilogis yang ditunjang dengan penelitian normatif yang seyogianya dilakukan dalam praktik. Artinya, penelitian yang telah dilakukan adalah penelitian empiris dan ditunjang dengan penelitian normatif 
terutama untuk menjawab peta jalan penelitian yang berkaitan dengan asas-asas hukum, sinkronisasi hukum serta perbandingan hukum.

\section{HASIL PENELITIAN}

Peneliti dalam penelitian ini telah melakukan kajian terhadap Peraturan Perundangundangan tentang Disabilitas, yaitu Undang-Undang No 8 Tahun 2016 Tentang Penyandang Disabilitas dan Peraturan Daerah No 3 Tahun 2015 Tentang Pemenuhan dan Perlindungan Hak-Hak Penyandang Disabilitas. Peneliti juga telah melakukan juga wawancara dengan berbagai Satuan Kerja Perangkat Daerah (SKPD) terkait.

Misalnya, Dinas Pekerjaan Umum Kota Padang, Dinas Sosial Kota Padang, Badan Penanggulangan Bencana Daerah Kota Padang, dan DPRD Kota Padang dan Persatuan Penyandang Disabilitas Indonesia (PPDI) Kota Padang. Tujuan umum dilakukan wawancara itulah untuk mengetahui sejauh mana program dinas-dinas terkait dan apa saja yang telah dilakukan dalam upaya memberikan pemenuhan, dan perlindungan terhadap hak-hak penyandang disabilitas di Kota Padang. Penyandang Disabilitas menurut Perda No 3 Tahun 2015 itu adalah setiap orang yang mengalami keterbatasan jasmani, rohani, intelektual, atau sensorik dalam jangka waktu lama yang dalam berinteraksi dengan lingkungan dan sikap masyarakatnya dapat mengalami hambatan dan kesulitan berpartisipasi secara penuh dan efektif dengan warga negara lainnya berdasarkan kesamaan hak.

Dari wawancara itulah maka dapat direkam berbagai informasi yang berkenan dengan pemenuhan, dan perlindungan terhadap hak-hak penyandang disabilitas di Kota Padang. Diantaranya adalah: Dinas Pekerjaan Umum telah membangun aneka fasilitas yang ramah terhadap kepentingan penyandang disabilitas. Diantaranya adalah berupa jalan dan trotoar di empat titik, yakni di Jalan Muhammad Yamin, Jalan Permindo, GOR H. Agus Salim, dan Taman Imam Bonjol. Ke empat titik itu menjadi pusat perhatian dan menjadi titik pertama kali yang dibangun oleh Dinas Pekerjaan Umum Kota Padang dalam memenuhi dan memberikan perlindungan terhadap hak-hak penyandang disabilitas karena disebabkan oleh Pertama, empat titik tersebut boleh dikatakan sebagai ikon kota Padang dalam pemenuhan terhadap hak-hak penyandang disabilitas di Kota Padang. Kedua menjadi pusat perekonomian dan perdagangan kota Padang (jalan Permindo II, jalan 
Muhaammad Yamin, dan GOR H. Agus Salim) dan sebagai pusat keramaian (baca: taman Imam Bonjol). Tempat warga kota Padang berinteraksi ekonomi dan melaksanakan jual beli serta melakukan rekreasi. Oleh karena hak tersebut merata dan dapat dinikmati oleh penyandang disabilitas maka ditempat itu dibuat fasilitas jalan yang dicat dengan warna kuning dan fasilitas ini sangat bermanfaat sekali bagi penyandang disabilitas tunanetra.

Berikut ini ditampilkan Data Penyandang Disabilitas Dinas Sosial Kota Padang.

Tabel 1

Data Penyandang Disabilitas Sejak Tahun 2014 s/d 2017

\begin{tabular}{|l|c|c|c|c|}
\hline $\begin{array}{c}\text { Jumlah Penyandang } \\
\text { Disabilitas per kecamatan }\end{array}$ & $\mathbf{2 0 1 4}$ & $\mathbf{2 0 1 5}$ & $\mathbf{2 0 1 6}$ & $\mathbf{2 0 1 7}$ \\
\hline Kecamatan Pauh & 191 & 207 & 207 & 210 \\
\hline Kecamatan Koto Tangah & 380 & 392 & 392 & 399 \\
\hline Kecamatan Lubuk Kilangan & 136 & 145 & 145 & 145 \\
\hline Kecamatan Padang Barat & 110 & 119 & 119 & 119 \\
\hline Kecamatan Padang Selatan & 211 & 222 & 222 & 225 \\
\hline Kecamatan Padang Timur & 87 & 98 & 98 & 100 \\
\hline Kecamatan Padang Utara & 200 & 212 & 212 & 217 \\
\hline Kecamatan Lubuk Begalung & 245 & 256 & 256 & 256 \\
\hline Kecamatan Kuranji & 161 & 172 & 172 & 172 \\
\hline Kecamatan Nanggalo & 133 & 142 & 142 & 147 \\
\hline Kecamatan Bungus Teluk Kabung & 72 & 80 & 80 & 80 \\
\hline \multicolumn{1}{|c|}{ Jumlah } & $\mathbf{1 . 9 2 6}$ & $\mathbf{2 0 4 5}$ & $\mathbf{2 0 4 5}$ & $\mathbf{2 0 7 0}$ \\
\hline
\end{tabular}

Sumber: Dinas Sosial Kota Padang dalam Data Jumlah Penyandang Disabilitas sejak tahun 2014 s/d 2017

Tabel 2

Data Jumlah Penyandang Disabilitas Menurut Jenis Disabilitas sejak Tahun 2014 s/d 2017

\begin{tabular}{|l|c|c|c|c|}
\hline $\begin{array}{c}\text { Data Jumlah Penyandang } \\
\text { Disabilitas }\end{array}$ & $\mathbf{2 0 1 4}$ & $\mathbf{2 0 1 5}$ & $\mathbf{2 0 1 6}$ & $\mathbf{2 0 1 7}$ \\
\hline Tuna Daksa (Cacat Fisik) & 361 & 380 & 380 & 390 \\
\hline Daksa Berat (Ganda) & 105 & 135 & 135 & 145 \\
\hline $\begin{array}{l}\text { Tuna Grahita, Autis, ADHD, } \\
\text { AKB/Learning Disability }\end{array}$ & 1.110 & 1.150 & 1.150 & $\begin{array}{c}1.15 \\
0\end{array}$ \\
\hline Tuna Rungu Wicara & 287 & 300 & 300 & 305 \\
\hline Tuna Netra & 63 & 80 & 80 & 80 \\
\hline \multicolumn{1}{|c|}{ Jumlah } & $\mathbf{1 9 2 6}$ & $\mathbf{2 0 4 5}$ & $\mathbf{2 0 4 5}$ & $\mathbf{2 0 7 0}$ \\
\hline
\end{tabular}

Sumber: Dinas Sosial Kota Padang dalam Data Jumlah Penyandang Disabilitas sejak tahun 2014 s/d 2017 
Berdasarkan Pasal 7 Ayat (1) Peraturan Daerah Kota Padang Nomor 3 Tahun 2015 tentang Pemenuhan dan Perlindungan Hak-hak Penyandang Disabilitas menyebutkan bahwa “ Jenis kedisabilatasan sebagaimana dimaksud dalam Pasal 6 meliputi : a) tunanetra, b) tunarunggu wicara, c) tunagrahita, d) tunadaksa, e) tunaganda, dan f) autis. Data yang disajikan diatas adalah data segala jenis kedisabilitasan yang ada di pemerintah Kota Padang. Berdasarkan penelitian yang dilakukan aneka fasilitas yang dibangun oleh Dinas Pekerjaan Umum Kota Padang adalah fasilitas untuk tunanetra. Pengertian Tunanetra adalah penyandang disabilitas yang mengalami keterbatasan, kelainan, ketidakmampuan dan disfungsi pada indra penglihatan.

Dari upaya yang dilakukan oleh Pemerintah Kota Padang melalui Dinas Pekerjaan Umum dan Tata Ruang Kota Padang telah melakukan sejumlah upaya untuk menuju Kota Padang sebagai kota yang ramah HAM. Pesatnya pembangunan fasilitas yang ramah hak asasi manusia yang dilakukan oleh Dinas Pekerjaan Umum Kota Padang karena pemerintah Kota Padang telah mengikrarkan diri untuk menjadi Kota yang Ramah HAM. Kota yang ramah HAM itu dimulai dari fasilitas yang ramah dan baik bagi penyandang disabilitas di Kota Padang.

Hasil penelitian ini dalam laporan akhir penelitian ini disampaikan dari informasi melalui wawancara dengan warga Kota Padang di empat titik yang menjadi lokasi penelitian, yakni Jalan Muhammad Yamin, Jalan Permindo II, GOR H. Agus Salim Kota Padang, dan Taman Imam Bonjol Kota Padang. Wawancara tersebut adalah dilakukan dengan Nasib Ebenezer yang beralamat di Tabing Kota Padang yang diwawancarai pada tanggal 12 Juli 2018 di Jalan Permindo II Kota Padang. Kemudian, Zulkifli Sikumbang yang diwawancarai pada tanggal 15 Mei 2018 di GOR H. Agus Salim Kota Padang juga mengatakan hal yang sama sudah ada perbaikan bagi fasilitas publik bagi penyandang disabilitas berupa trotoar di Kota Padang dan ia pun mengharapkan agar Gubernur Sumatera Barat, Wali Kota Padang dan Dinas Sosial Kota Padang agar lebih memperhatikan kepentingan penyandang disabilitas. Yang melingkupi seluruh jenis disabilitas baik yang disabilitas penglihatan, pendengaran dan disabilitas-disabilitas lainnya. Kemudian, Emi seorang warga Kota Padang yang beralamat di Seberang Padang Kota Padang yang diwawancarai pada tanggal 15 Mei 2018 di jalan Permindo II Kota 
Padang juga mengapresiasi jalan trotoar yang dibangun untuk penyandang disabilitas dan ia pun mengharapkan agar trotoar yang sama lebih banyak dibangun lagi di Kota Padang.

Wawancara dengan Ketua Komisi IV Bidang Kesejahteraan Rakyat (Kesra) DPRD Kota Padang H. Maidestal Hari Mahesa, S.Sos., M.M terkait dengan Pelayanan Publik Bagi Penyandang Disabilitas di Kota Padang ketika diminta tanggapannya terhadap adanya keluhan Persatuan Penyandang Disabilitas Indonesia Kota Padang terhadap fasilitas publik yang dinilai belum ramah disabilitas, ia mengatakan setidaknya ada beberapa hal. Pertama, masih lemahnya koordinasi antara Organisasi Perangkat Daerah (OPD) di Pemerintah Kota Padang dalam mengurusi fasilitas publik yang ramah dengan penyandang disabilitas sehingga belum satu pandangan dalam melihat persoalan disabilitas. Kedua, kontraktorkontraktor yang melaksanakan pembangunan jalan trotoar belum memahami tentang kebutuhan penyandang disabilitas. Kontraktor-kontraktor juga belum mempunyai pengetahuan khusus tentang kebutuhan disabilitas.

Artinya, kelemahan selama ini terletak di perencanaan. Misalnya, adanya penghalang berupa tonggak reklame, tiang listrik, kendaraan yang parkir liar pada jalur jalan yang dilalui penyandang disabilitas, sehingga ini menyulitkan penyandang disabilitas dalam mengakses pelayanan publik, Ketiga, deklarasi yang digaungkan oleh pemerintah Kota Padang tentang Kota Padang yang ramah disabilitas harus kembangkan dan ditindaklanjuti dan jangan sampai hanya berhenti pada tingkat deklarasi. Komitmen pemerintah Kota Padang sudah ada dalam pemenuhan dan perlindungan penyandang disabilitas. Hal ini dibuktikan dengan adanya Peraturan Daerah Kota Padang Nomor 3 Tahun 2015 Tentang Pemenuhan dan Perlindungan Hak-Hak Penyandang Disabilitas dan implementasi Peraturan daerah itu dibuktikan oleh DPRD Kota Padang dengan menyetujui anggaran untuk kepentingan penyandang disabilitas dan dilaksanakan oleh Pemerintah Kota Padang melalui Dinas Pekerjaan Umum dan Penataan Ruang Kota Padang dengan membangun fasilitas publik yang ramah disabilitas.

Menurut Kepala Dinas Dinas Pekerjaan Umum dan Penataan Ruang Kota Padang Fatriarman Noer mengatakan menjamin seluruh trotoar yang dibangun tergolong ramah disabilitas. Oleh karena itu pihaknya meminta masyarakat untuk bersabar karena saat ini proses pembangunan sedang berlangsung. Trotoar itu semuanya ramah disabilitas. Menurut Ketua Persatuan Penyandang Disabilitas Indonesia Kota Padang Icun Suheldi 
mengatakan, persoalan yang dikeluhkan masih banyaknya ditemukan penghalang seperti tiang listrik, tiang telpon, parkir kendaraan di trotoar dan hambatan lainnya. Keluhan itu ditemukan ketika dilaksanakan cek lapangan oleh PPDI Kota Padang yang dimulau dari samping KFC Ahmad Yani menelusuri pedestrian Pattimura, berbelok ke Jalan Belakang Olo, di perempatan jalan bekalang olo menuju jalan Bandar Olo dan menyeberang untuk selanjutnya terus arah jalan Pattimura.

Icun mengatakan, masih ada kekurangan seperti hambatan tiang listrik dan tiang telpon di atas trotoar, harusnya bebas hambatan. Ketua PPDI Kota Padang berharap tiangtiang yang ada ditengah trotoar bisa dipindahkan ke pinggir trotoar agar tidak menganggu aktivitas pejalan kaki terutama penyandang disabilitas. Namun tidak dapat dipungkiri di Kota Padang saat ini berdasarkan penelitian yang dilakukan selama enam bulan menyimpulkan bahwa sudah ada beberapa titik yang sudah baik fasilitas publik penyandang disabilitasnya. Hal itu dapat dilihat dari wawancara yang peneliti lakukan dengan warga Kota Padang di Jalan M. Yamin, jalan Permindo II, Taman Imam Bonjol dan GOR H. Agus Salim Kota Padang mereka mengatakan fasilitas publik bagi penyandang disabilitas sudah membaik dan mereka mengharapkan agar Pemerintah Kota Padang agar lebih banyak lagi membangun fasilitas publik berupa trotoar yang ramah bagi penyandang disabilitas sehingga kesempatan dan hak penyandang disabilitas menikmati fasilitas publik sama dengan warga lain di Kota Padang.

Hal itu disampaikan oleh salah seorang warga Kota Padang yang bernama Nasib Ebenezer yang beralamat di Tabing Kota Padang yang diwawancarai pada tanggal 12 Juli 2018 di Jalan Permindo II Kota Padang. Kemudian, Zulkifli Sikumbang yang diwawancarai pada tanggal 15 Mei 2018 di GOR H. Agus Salim Kota Padang juga mengatakan hal yang sama sudah ada perbaikan bagi fasilitas publik bagi penyandang disabilitas berupa trotoar di Kota Padang dan ia pun mengharapkan agar Gubernur Sumatera Barat, Wali Kota Padang dan Dinas Sosial Kota Padang agar lebih memperhatikan kepentingan penyandang disabilitas. Yang melingkupi seluruh jenis disabilitas baik yang disabilitas penglihatan, pendengaran dan disabilitas-disabilitas lainnya.

Kemudian, Emi seorang warga Kota Padang yang beralamat di Seberang Padang Kota Padang yang diwawancarai pada tanggal 15 Mei 2018 di jalan Permindo II Kota 
Padang juga mengapresiasi jalan trotoar yang dibangun untuk penyandang disabilitas dan ia pun mengharapkan agar trotoar yang sama lebih banyak dibangun lagi di Kota Padang. Akan tetapi Pemerintah Kota Padang melalui Dinas Pekerjaan Umum dan Penataan Ruang Kota Padang sedang membangun fasilitas publik berupa jalan trotoar dengan anggaran dari Anggaran Pendapatan dan Belanja Daerah (APBD) Kota Padang Tahun 2018, salah satunya adalah sepanjang jalan Ujung Gurun Kota Padang. Hal ini ditujukan untuk menjadikan Kota Padang sebagai Kota yang Ramah Disabilitas.

Luaran penelitian yang ingin dicapai adalah artikel ilmiah yang dimuat di Jurnal Nasional Terakreditasi. Penelitian ini juga dimaksudkan sebagai bahan masukan dari pemerintah Kota Padang dalam mengambil keputusan terkait dengan disabilitas serta sebagai bahan pengayaan pada bahan ajar dalam mata kuliah Hukum dan HAM di Fakultas Hukum Universitas Ekasakti Padang. Namun, hasil dan luaran tersebut akan peneliti usahakan untuk mencapainya hingga akhir Desember 2018 ini. Saat ini sudah ada draftnya dan akan dimasukkan ke dalam jurnal pada akhir tahun ini. Jenis luaran yang akan diutamakan adalah berupa artikel ilmiah di jurnal nasional terakreditasi sedangkan bahan ajar belum dapat peneliti penuhi. Dalam usaha untuk mencapainya itu maka peneliti mohon bimbingan dan arahan agar target luaran itu tercapai. Dari penelitian yang dilakukan menunjukkan bahwa trotoar yang ada saat ini ternyata belum nyaman bagi penyandang disabilitas.

\section{PENUTUP}

Pemerintah Kota Padang telah mencanangkan Kota Padang akan dijadikan Kota yang Ramah HAM. Upaya untuk mewujudkan itu telah dilakukan dengan pembangunan sarana dan prasarana berupa pembangunan jalan dan trotoar di empat titik strategis di Kota Padang, yakni di Jalan Muhammad Yamin, Jalan Permindo II, GOR H. Agus Salim dan Taman Imam Bonjol Padang. Pembangunan fasilitas pelayanan publik yang didanai oleh Pemerintah Kota Padang itu mendapat dukungan dari DPRD Kota Padang dan Komnas HAM Perwakilan Sumatera Barat. 


\section{DAFTAR PUSTAKA}

\section{Koran :}

Harian Padang Ekspres, 12 November 2018

Wawancara :

Wawancara dengan Ketua Komisi IV DPRD Kota Padang H. Maidestal Hari Mahesa, Jum, at, 16 November 2018.

Wawancara dengan Nasib Ebenezer di Jalan Permindo II, 12 Juli 2018

Wawancara dengan Emi di jalan Permindo II, 15 Mei 2018

Wawancara dengan Zulkifli Sikumbang di GOR H. Agus Salim , 15 Mei 2018

Wawancara dengan Lukman di GOR H. Agus Salim, 7 Juli 2018

Wawancara dengan Muhammad Kohir di Jalan M. Yamin, 15 Mei 2018

Wawancara dengan Ari di jalan M. Yamin , 7 Juli 2018

Wawancara dengan Herman di Taman Imam Bonjol, 15 Mei 2018 